\title{
NILAI PENDIDIKAN DALAM SASTRA LISAN LAWAS (PUISI RAKYAT) MASYARAKAT SUMBAWA DAN POTENSINYA SEBAGAI MATERI AJAR DI SEKOLAH
}

\author{
(THE EDUCATIONAL VALUES IN LAWAS, ORAL LITERATURE OF \\ SAMAWA PEOPLE AND ITS POTENCIAL \\ TO BE LEARNING MATERIAL IN SCHOOL)
}

\author{
Heni Mawarni ${ }^{1}$, Ubaidullah ${ }^{2}$ \\ ${ }^{1}$ Universitas Sebelas Maret Surakarta \\ ${ }^{2}$ Universitas Samawa \\ Ponsel: 082341039945 \\ Pos-el: henimawarni@student.uns.ac.id ${ }^{1}$, ubaidunsa@gmail.com ${ }^{2}$ \\ Diterima: 1 Oktober 2019; Direvisi:4 Desember 2019; Disetujui: 4 Desember 2019 \\ DOI https://doi.org/10.26499/mab.v13i2.265
}

\begin{abstract}
Abstrak
Penelitian ini bertujuan untuk mendeskripsikan nilai-nilai pendidikan dalam sastra lisan lawas (puisi rakyat) masyarakat Sumbawa. Lawas telah menjadi bagian dari tonggak kehidupan masyarakat sehingga perlu diungkapkan nilai-nilai yang terdapat di dalamnya. Penelitian ini merupakan penelitian deskriptif kualitatif. Data dikumpulkan dengan teknik wawancara dan analisis dokumen. Data dianalisis dengan teknik ketekunan pengamatan dengan pemusatan pada hal-hal yang dicari secara rinci sehingga data-data yang ditemukan peneliti akan semakin benar. Dengan begitu data-data yang ditemukan benarbenar mengandung nilai pendidikan. Berdasarkan hasil analisis data ditemukan nilai pendidikan yang terkandung dalam lawas (puisi rakyat) masyarakat Sumbawa Nusa Tenggara Barat: (1) nilai sosial, (2) nilai moral, (3) nilai religius, dan (4) nilai budaya. Nilai pendidikan yang terkandung dalam lawas tidak terlepas dari nilai-nilai luhur yang selalu menjadi pedoman dalam kehidupan masyarakat Sumbawa.
\end{abstract}

Kata kunci: puisi; sastra; lawas Sumbawa; nilai-nilai pendidikan

\begin{abstract}
This study aims to describing the educational values contained in oral literature lawas (folk poetry) of the Sumbawa people who have become part of the milestone of people's lives so it is necessary to disclose the values contained therein. This research is a qualitative descriptive study. Data collected by interview techniques, and document analysis. Data were analyzed by observing persistence techniques by focusing on the things sought in detail, so that the data found by researchers would be more correct that the data truly contained educational value. Based on the analysis of educational value data contained in lawas (folk poetry) the people of Sumbawa, West Nusa Tenggara can be concluded as follows; (1) social values, (2) moral values, (3) religious values, and (4) cultural values. The education value contained in the legacy is inseparable from the noble values that have always been a guideline in the life of the Sumbawa people.
\end{abstract}

Keywords: poetry; literature; education; lawas Sumbawa; the value of education 


\section{Pendahuluan}

Apresiasi sastra puisi dan pantun, dalam pembelajaran sastra di sekolah terdengar mengalami banyak kegagalan. Pada saat diamati dan dinilai, proses pembelajaran sastra berlangsung kurang menarik perhatian peserta didik, bahkan cenderung membosankan. Materi tentang apresiasi sastra pada hakikatnya merupakan upaya untuk menanamkan rasa peka kepada peserta didik terhadap cita rasa sastra. Seharusnya pengajaran apresiasi sastra yang disampaikan guru kepada peserta didik mampu mengubah sikap peserta didik dari acuh tak acuh menjadi lebih bersimpati terhadap sastra. Hal itu dikarenan materi sastra yang disuguhkan tidak sekadar representation of life (imitation of life) melainkan interpretation of life (Suwardi Endaswara, 2013:7). Dengan demikian, karya sastra harus dipahami sebagai fenomena yang tidak hanya sekadar memuaskan emosi melainkan menanamkan ide-ide dan pikiran. Karya sastra sebagai salah satu kebutuhan manusia menawarkan kisi-kisi kemanusiaan yang indah menuju kesempurnaan hidup.

Kenyataan lain membuktikaan bahwa yang menjadi kendala dalam pembelajaran apresiasi sastra di sekolah adalah pemanfaatan buku yang tersedia di perpustakaan yang bergenre sastra belum maksimal. Kondisi seperti itu menjadikan minat belajar peserta didik, khususnya minat membaca masih sangat rendah. Faktor ketersediaan waktu, manajemen perpustakaan sekolah, dan dorongan dari guru ikut menjadi penyebab dalam hal ini. Berbagai kendala di atas menyebabkan pembelajaran sastra dalam berbagai jenjang pendidikan formal hingga saat ini belum mencapai sasaran sebagaimana yang diharapkan. Pada akhirnya pembelajaran sastra yang bertujuan menumbuhkan dan meningkatkan apresiasi sastra pada peserta didik belum mengembirakan. Peserta didik hanya sekadar menghafalkan nama-nama sastrawan dan karyanya saja. Mereka hanya mengenal sastra dari segi teorinya saja, tanpa mengetahui nilai yang terdapat dalam teks sastra. Hal semacam ini yang perlu diatasi dalam dunia pendidikan agar peserta didik tidak hanya mengenal sastra dari kulit luarnya saja. Peserta didik diharuskan menelaah lebih dalam teks karya sastra tersebut dan menemukan keindahan yang terdapat di dalamnya. Menggali keindahan di dalam karya secara tidak langsung menjadikan peserta didik mampu menemukan nilai-nilai yang 
terkadung dalam suatu karya sastra dan menerapkannya dalam kehidupan seharihari. Kegiatan seperti itu sangat penting karena apresiasi puisi dalam hal pemberian makna atau konkretisasi puisi selama ini belum tergarap dengan maksimal.

$\begin{array}{ccc}\text { Vala } & (2011: 526) & \text { dalam } \\ \text { penelitiannya } & \text { membuktikan } & \text { bahwa } \\ \text { memperkenalkan } & \text { peserta didik } & \text { dengan } \\ \text { puisi membawa } & \text { pengaruh yang positif }\end{array}$
bagi perkembangan karakternya. Oleh karena itu, puisi sangat efektif dalam pembelajaran. Salah satu sumber belajar peserta didik bisa diperoleh dari pengetahuan budaya lokal, misalnya dari sastra lisan atau puisi rakyat yang tertdapat dalam masyarakat. Salah satu puisi rakyat yang ada di Indonesia, yaitu puisi rakyat masyarakat Sumbawa yang biasa disebut dengan lawas. Lawas merupakan puisi rakyat yang ditulis menggunakan bahasa Sumbawa. Puisi rakyat yang digunakan untuk menuangkan isi hati seseorang terhadap lawan bicaranya ini bisa berkaitan dengan agama, sosial, pendidikan, dan nasihat. Oleh karena itu, puisi rakyat bisa dijadikan sebagai bahan ajar yang efektif dalam pembelajaran sastra dengan menggali nilai-nilai yang terkandung di dalamnya.

\section{Landasan Teori}

\subsection{Pembelajaran Sastra}

Pembelajaran sastra dapat membantu meningkatkan keterampilan, rasa cinta, dan penghargaan peserta didik terhadap bahasa dan sastra sebagai bagian dari budaya warisan leluhur. Melalui karya sastra, guru dapat mentransfer kandungan pesan dan nilai kepada penikmatnya. Oleh karena itu, untuk mengembangkan materi pembelajaran sastra lisan lawas, guru harus memberikan kesempatan kepada peserta didik untuk mengungkapkan pendapat dalam menanggapi suatu karya sastra, baik sastra lisan maupun tulisan. Hal itu dilakukan dengan mengubah paradigma pembelajaran sastra, baik secara teoritiskonseptual maupun dari segi teknik implementasinya, seperti metode, strategi, materi, langka-langka penyajian, media pembelajaran, evaluasi, dan lebih penting lagi dalam perumusan tujuan pembelajaran.

Materi tentang lawas di dalam kurikulum 2013 terdapat dalam mata Pelajaran Bahasa Daerah kelas $\mathrm{X}$ semester 2. Dalam pembelajaran lawas (puisi rakyat), guru tentu harus menjelaskan nilai-nilai yang terkandung di dalamnya. Dengan begitu, peserta didik 
akan mencermati dan menerapkannya dalam kehidupan sehari-hari.

Sebagaimana diketahui bahwa kajian sastra tidak hanya membahas puisi rakyat, tetapi juga prosa dan drama. Penelitian ini difokuskan pada lawas (puisi rakyat) karena lebih mudah untuk menanamkan pendidikan pada anak. Hal ini dikarenakan adanya penggunaan bahasa yang singkat serta gaya bahasa dan pemilihan katanya yang mudah dimengerti oleh anak.

Seorang guru harus memilih cara dan metode yang bisa menarik perhatian anak muridnya agar tidak merasa bosan. Selain itu, materi yang disampaikan guru tentunya harus bisa dipahami siswa. Salah satunya melalui pembelajaran sastra lawas (puisi rakyat).

Sastra, termasuk puisi tidak bisa dilepaskan dari estetika. Estetika adalah keindahan dan keindahan ini harus yang mengandung kualitas bahasa yang baik dan memiliki makna. Jika tidak ada makna maka puisi tidak akan memiliki arti dan jika tidak memiliki arti maka puisi tidak akan dikatakan memiliki nilai estetika.

Ritme, rima, puisi, lagu dan narasi pendek telah banyak digunakan dalam bidang pendidikan dan bidang terkait untuk terhubung dengan peserta didik, menyampaikan informasi, mendorong refleksi, memprovokasi kesadaran, meningkatkan kecerdasan emosi, meningkatkan harga diri, dan menginspirasi kreativitas (Cantor, 2006; Abernathy, 2017; Mayer et al., 2004; Kloser, 2013; Lafrenière, dkk, 2013; Whalen, 2009; Simecek, 2015; Wellbery, 2006). Jika menggunakan prosa (cerita) maka akan bercerita dahulu dan akan membutuhkan waktu yang banyak, begitu pula drama. Berbeda dengan pantun yang bahasanya singkat, padat, jelas dan mengandung keindahan. Oleh karena itu, peneliti memilih lawas (puisi rakyat) dan akan dianalisis tentang nilai pendidikan yang ada di dalamnya. Pada tahap selanjutnya melalui lawas (puisi rakyat diharapkan bisa menumbuhkan karakter yang baik pada peserta didik.

Teeuw (1988:51) menyatakan bahwa karya sastra menggabungkan sifat utile dan dulce. Pernyataan tersebut menunjukkan bahwa karya sastra berfungsi memberikan ajaran moral kepada manusia. Keterlibatan dalam karya sastra dapat menjadikan manusia responsif terhadap hal-hal luhur atau budaya yang telah diwariskan oleh leluhur. Salah satu sastra lisan yang 
diwariskan oleh leluluh masyarakat Sumbawa adalah lawas.

\subsection{Hakikat Lawas}

Lawas merupakan puisi rakyat yang menggunakan bahasa Sumbawa baik lisan maupun tulisan untuk mengekspresikan atau mengungkapkan perasaan hati dalam berbagai peristiwa. Juanda (2016) menyatakan, lawas adalah sastra lisan yang dimanfaatkan oleh masyarakat Sumbawa untuk mengungkapkan isi hati kepada pembaca dan lawan bicara (penikmat/pendengar). Sehubungan dengan hal tersebut, Rayes (dalam Suyasa, 2009:92) mengemukakan bahwa lawas sebagai puisi rakyat diciptakan oleh manusia dan dinyatakan dengan menggunakan bahasa lisan maupun tulisan yang menggambarkan rasa keindahan dan keharuan dalam lubuk jiwa manusia. Mawarni menyatakan "Lawas (folk poetry) is an oral literature (folk poetry) of the Sumbawa people. Until now, it is still developing and used to express the contents of the heart to the interlocutors delivered at certain times both individually and in groups." (Lawas adalah sastra lisan (puisi rakyat) masyarakat Sumbawa yang hingga saat ini masih terus berkembang di tengahtengah masyarakat sebagai alat untuk mengungkapkan perasaan kepada lawan tutur baik secara individu maupun secara kelompok). Lawas terdiri atas tiga baris dalam satu bait, tiap baris terdiri dari 8 suku kata (Zuhdi, 2017:332).

Dari beberapa pendapat para ahli di atas dapat disintesiskan bahwa lawas merupakan puisi rakyat masyarakat Sumbawa yang digunakan untuk menyampaikan isi hati kepada orang lain. Isi lawas berkaitan dengan agama, pendidikan, dan nasihat yang tersusun indah dalam tiga baris per bait dan setiap baris terdiri atas delapan suku kata.

\subsection{Nilai Pendidikan}

Nilai merupakan sesuatu yang dianggap baik, indah, benar, layak, dan penting oleh manusia dalam kehidupan bermasyarakat. Zakiyah (2014:15) menyatakan nilai adalah segala hal yang berhubungan dengan tingkah laku manusia mengenai baik atau buruk yang diukur oleh agama, tradisi, etika, moral, dan kebudayaan yang berlaku dalam masyarakat. Williams (Macionis, 1970:33) mengemukakan bahwa nilai adalah "what is desirable, good or bad, beautiful or ugly" (Apa yang diinginkan, baik atau buruk, indah atau jelek). Menurut Gani (1988: 287), nilai tidak dapat dipisahkan dari masyarakat baik secara individu maupun kelompok. Hal 
itu dikarenakan manusia menjadikan nilai sebagai motivasi dalam bersosialisasi dengan orang lain dalam kondisi sadar atau tidak sebagai pilihan yang diinginkan. Dari beberapa pengertian tersebut dapat disintesiskan bahwa nilai adalah segala sesuatu yang berhubungan dengan baik buruknya tingkah laku yang dimiliki oleh seseorang, baik untuk dirinya sendiri maupun untuk orang lain

Banyak pandangan para ahli mengenai (pendidikan), salah satunya Damadi (2010) yang mengklasifikasikan nilai dalam beberapa bagian, yakni (1) nilai kenikmatan, (2) nilai kehidupan, (3) nilai kejiwaan, dan (4) nilai kerohanian. Proses pemberian nilai juga memiliki keterkaitan dengan pendidikan yang dimiliki oleh seseorang

Farhurrohman dan Sulistyorini (2012:2) menyatakan, pendidikan merupakan situasi belajar dan pengalaman belajar yang berlangsung sepanjang hidup manusia dan memengaruhi pertumbuhan hidup dalam lingkungan secara individu. Selanjutnya, Tilaar, (2015:27) mengemukakan bahwa pendidikan adalah wujud dalam pembangunan nasional dan salah satu aspek pembangunan yang sekaligus merupakan salah satu aspek terpenting yang dijadikan acuan untuk mencapai kondisi terbaik dalam hidup serta sekaligus merupakan upaya untuk menyiapkan dan merekayasa arah perkembangan masyarakaat. Salah satu aspek penting sebagai acuan untuk mencapai kondisi terbaik dalam hidup adalah pendidikan (Saroni, 2012:63). Pendidikan dapat diartikan sebagai upaya untuk mengoptimalkan (a) potensi manusiawi, (b) kecakapan hidup, dan (c) sikap kepribadian peserta didik menuju kesempurnaan dan kedewasaan yang baik dalam mengoptimalkan perkembangan hidup (Suparlan, 2015:7).

Nilai pendidikan adalah nilai-nilai yang dapat mengubah pertumbuhan hidup seseorang untuk mengubah situasi pertumbuhan hidupnya. Venkatalah (2007:3) menyatakan bahwa nilai pendidikan dalam kehidupan manusia dibagi menjadi lima bagian, yakni nilai pribadi, nilai sosial, nilai-nilai moral, nilai spiritual, dan nilai perilaku. Sementara itu, Sarumpet (2002:43) berpendapat bahwa terdapat empat wilayah fundamental yang menjadi sumber dalam penciptaan suatu karya sastra yaitu, (1) agama, (2) sosial, (3) budaya, dan (4) individual. 
Nilai-nilai dalam kehidupan seharihari biasanya dituangkan dalam sebuah karya dengan tujuan untuk memberikan tunjuk ajar kepada pembaca atau penikmatnya. Pantun merupakan karya yang sering digunakan orang untuk memberikan tunjuk ajar. Pantun identik dengan suku Melayu dikarenakan zaman dahulu nenek moyang sudah terbiasa menyelingi percakapan dengan pantun sehingga keberadaannya menjadi sangat diperlukan sebagai media penyampai pesan moral dan tunjuk ajar.

Hal yang dapat dilakukan untuk menanamkan nilai pendidikan kepada peserta didik adalah dengan mengulas kembali karya sastra baik lisan maupun tulisan yang mengandung nilai-nilai luhur budaya bangsa atau berupa seni pertunjukan (Sunaryadi, 2013:120; Solihati, 2017). Sastra lisan puisi mengungkapkan nilai kearifan budaya dalam suatu masyarakat (Suwignyo, 2013).

Media pembelajaran yang digunakan untuk mendidik adalah media pembelajaran yang mengandung nilai didik. Menumbuhkan nilai pendidikan untuk anak juga harus dilakukan di Sekolah. Sekolah adalah sarana kedua seorang anak untuk mencari ilmu. Dalam sebuah karya sastra dapat ditemukan berbagai nilai-nilai pendidikan yang memiliki kebijaksanaan yang dapat ditanamkan kepada anak-anak atau peserta didik.

\subsection{Hakikat Puisi}

Puisi adalah karya sastra yang ditulis menggunakan bahasa sebagai kualitas estetikanya (Mihardja, 2012:18). Nurgiyantoro, 2015) menyatakan bahwa fungsi keindahan dalam puisi tidak sekadar terkait dengan keindahan bunyi (misalnya yang berupa keindahan persajakan), tetapi juga ketepatan makna yang dikandung di dalamnya sehingga bisa dijadikan sebagai media penyampaian pesan-pesan tertentu. Sastra puisi dibagi menjadi dua, yakni puisi lama dan puisi baru. Puisi lama juga sering dikatakan sebagai pantun.

Pantun adalah puisi lama yang dikenal sangat luas dalam bahasa-bahasa nusantara. Pantun terdiri atas 4 larik dengan rima akhir $\mathrm{a} / \mathrm{b} / \mathrm{a} / \mathrm{b}$. Setiap larik biasanya terdiri atas 4 kata, larik $1-2$ sebagai sampiran, larik 3-4 sebagai isi (Pradopo, 2012:9 dan Zaidan, dkk. 1994:143). R.O. Winsted (www.ilmusiana.com, diakses tanggal 1 September 2018) menyatakan bahwa pantun bukanlah sekadar kata-kata yang mempunyai rima dan irama, melainkan juga rangkaian kata yang indah untuk 
menggambarkan isi hati dan kehangatan, seperti (1) cinta, (2) kasih sayang, dan (3) rindu dendam penuturnya yang mengandung ide kreatif dan kritis serta padat kandungan maknanya.

Suseno (2006) menyatakan bahwa pantun biasa digunakan untuk:

1. alat komunikasi masyarakat;

2. adat istiadat:

a) perkawinan

b) tepak sirih, dan lain-lain;

3. menghibur dan menidurkan anak; dan

4. menyampaikan nasihat.

Hamilton (2004) menyatakan bahwa pantun terkadang menjadi dendang atau nyanyian orang tua, khususnya kaum ibu untuk menghantarkan anaknya tidur. Pantun seperti ini biasanya berupa pantun yang berbentuk cerita atau nasihat.

Dalam pantun seringkali ditemukan nasihat-nasihat untuk menjalani kehidupan. Nasihat tersebut sangat baik dijadikan pedoman tuntunan hidup. Dalam pantun terdapat nilai pendidikan beragama, moral, maupun budaya. Berbicara mengenai nilai, bisa dipastikan bahwa setiap karya sastra yang dihasilkan mengandung nilai-nilai kehidupan. Nilai merupakan tolok ukur seseorang dalam menimbang baik buruknya sifat atau perilaku.
Berdasarkan paparan di atas, maka rumusan masalah dalam penelitian ini adalah nilai pendidikan dalam sastra lisan lawas (puisi rakyat) masyarakat Sumbawa dan potensinya sebagai materi ajar di kelas.

\section{Metode Penelitian}

Penelitian ini menggunakan pendekatan deskriptif kualitatif. Moleong (2010: 6) menyatakan bahwa penelitian kualitatif adalah penelitian yang mengkaji fenomena yang terjadi sesuai fakta yang dialami oleh subjek. Penelitian kualitatif berhubungan dengan perilaku, tindakan, dan motivasi secara holistik dengan cara deskripsi dalam bentuk kata-kata dan bahasa pada suatu konteks khusus yang alamiah dan dengan memanfaatkan berbagai metode ilmiah. Pengumpulan data menggunakan metode observasi, menyimak, wawancara, dan analisis dokumen. Menurut Lofland dalam (Moleong, 2010:157), sumber utama data penelitian kualitatif ialah tindakan, katakata, dan data dokumen. Sumber data dalam penelitian ini adalah masyarakat Kabupaten Sumbawa Nusa Tenggara Barat dan dokumen. Pengumpulan data dalam penelitian ini, yaitu (1) mencari data yang dianggap sebagai data (2)

238 | Mabasan, Vol. 13, No. 2, Desember 2019, hlm. 231-246

p-ISSN: 2085-9554, e-ISSN: 2621-2005 
menggolongkan data yang sudah terkumpul, (3) menganalisis data-data yang mengandung nilai pendidikan.

Pengecekan keabsahan adalah cara terbaik untuk menghilangkan perbedaanperbedaan konstruksi kenyataan yang ada dalam konteks suatu studi sewaktu mengumpulkan data tentang berbagai kejadian dan hubungan dari berbagai pandangan (Moleong, 2010:332). Teknik yang dilakukan peneliti untuk pengecekan keabsahan data adalah ketekunan pengamatan, yaitu menemukan ciri-ciri dan unsur-unsur dalam situasi yang sangat relevan dengan persoalan yang sedang dicari kemudian memusatkannya pada hal-hal tersebut secara rinci. Dengan melakukan ketekunan pengamatan, datadata yang ditemukan peneliti merupakan data yang benar-benar mengandung nilai pendidikan.

\section{Pembahasan}

\subsection{Identifikasi}

Lawas

yang

\section{Mengandung Nilai Pendidikan}

Berdasarkan hasil pengumpulan data maka disaring lawas-lawas (puisi tradisional) Sumbawa yang mengandung nilai-nilai pendidikan di dalamnya yaitu sebagai berikut.

\subsubsection{Nilai Pendidikan Agama atau Religius}

Nilai agama merupakan cerminan dari sikap ataupun perilaku manusia atau makhluk hidup terhadap Tuhan yang didasari pada kaidah yang dianut. Zakiyah (2014:143-144) menyatakan bahwa nilai agama adalah nilai tentang ketaatan kepada Allah Swt. dan nilai yang mengatur hubungan sesama manusia yang ditanamkan melalui proses pendidikan ajaran agama Islam. Nilai pendidikan agama atau religius terdapat dalam lawas berikut.

Ya mubuya nyata iman

Tili leng godong ma'rifat

Leng selak syukur ke sabar

(Kau cari nyatanya iman

Tertutup tabit daun ma'rifat

Di antara perasaan syukur dan kesabaran)

Kutipan lawas tersebut menggambarkan bahwa manusia selaku makhluk yang bertaqwa kepada Allah harus mengutamakan rasa syukur dan kesabaran seperti pada baris ketiga Leng selak syukur ke sabar sebagai implementasi keimanan.

Lawas anak-anak

Cik cik lema tu meracik

Cik cik bawi nanta kuntung

Tau licik kena tuntung

(Cik cik ayo kita marancik/bermain Mabasan, Vol. 13, No. 2, Desember 2019, hlm. 231-246 p-ISSN: 2085-9554, e-ISSN: 2621-2005 | 239 
Cik cik adu kasihan sang babi buntung Orang yang tidak masuk sekolah kena pukul)

Kutipan tersebut biasanya dilantunkan oleh anak-anak ketika sedang bermain bersama. Baris ketiga berisi peringatan kepada anak-anak agar tidak terlalu asik bermain sampai akhirnya tidak masuk sekolah atau tidak pergi mengaji. Jika hal itu dilakukan biasanya guru memberikan hukuman berupa pukulan kepada orang yang tidak masuk sekolah tersebut.

Kusamula ke bismilla

Kusasuda ke wasalam

Nanke salamat parana

(Kumulai dengan bismilah

Kuakhiri dengan wasalam

Semoga aku selamat)

Kutipan lawas di atas selalu hadir di awal pertunjukan sebagai ucapan pembuka menurut keyakinan agama (Islam) dalam suatu pertunjukan balawas. Kalimat tersebut merupakan kalimat kalimat pujian kepada Allah. Orang yang mendengar teks tersebut secara psikologis akan selalu ingat pada kebesaran Allah. Lawas seperti itu bukan hanya pelengkap, tetapi juga sebagai ajakan untuk selalu bertakwa kepada Tuhan.

Ngungku mo kau we ayam Lema ku to rua shubu Les ano ngasih mo ate
(Berkokoklah kau wahai ayam Cepat kita tau waktunya shubu Keluar matahari tenanglah hati)

Lawas itu biasanya disampaikan pada waktu subuh dengan menggunakan irama dan tempo lagu yang lembut untuk menandakan waktu subuh telah tiba, sekitar pukul 03.00-05.00. Lawas itu dilantunkan agar semua umat Islam yang ada di pulau Sumbawa melakukan salat subuh.

Nilai pendidikan agama atau religius yang terkandung dalam empat lawas di atas adalah sikap untuk selalu bersyukur dalam melakukan berbagai kegiatan yang dilakukan. Dalam melakukan berbagai kegiatan hendaknya selalu terlebih dahulu mengucapkan bismillah dan menyebutkan nama Allah. Sesibuk apapun hendaknya jangan lupa untuk belajar mengaji dan jangan pernah tinggalkan salat.

\subsubsection{Nilai Pendidikan Budaya Sejarah}

Nilai budaya merupakan nilai yang dianggap baik oleh suatu kelompok masyarakat atau suku bangsa yang belum tentu dipandang baik pula oleh kelompok masyarakat atau suku bangsa lain sebab nilai budaya membatasi dan memberikan karakteristik pada suatu masyarakat dan

240 | Mabasan, Vol. 13, No. 2, Desember 2019, hlm. 231-246

p-ISSN: 2085-9554, e-ISSN: 2621-2005 
kebudayaannya. Adapun lawas yang mengandung nilai budaya sebagai berikut.

\section{Lalo kau salonang Bong}

Datang Jong kubeli genti

Liwat nan adasi lili

(Lepaslah kau hiasan pemabuk asmara Datang jung kubelikan ganti Lebih dari itu kudapatkan penggantimu)

Bong adalah alat hisap candu yang dalam bahasa Samawa disebut piyen. Bong adalah simbol dari wanita penggoda, dan jong adalah perahu layar dari negeri Cina yang dalam bahasa Samawa disebut jung. Lawas ini diucapkan oleh seorang pria yang ditujukan kepada seorang wanita pujaan hati yang telah mengecewakan atau menolak cintanya. Dia berjanji akan mencari penggantinya yang lebih baik.

Lawas ini menunjukkan secara tersurat bahwa pelawas (pujangga) pada masa lalu membuat perumpamaan dari apa yang pernah dilihat dan didengar untuk diikat dalam lawas. Bong dan jong merupakan sesuatu yang tidak lepas dari sejarah dan budaya Cina. Para pedagang cina sudah pernah melakukan hubungan dagang sejak dulu dengan Sumbawa sehingga orang Sumbawa mengenal candu yang dalam bahasa Sumbawanya disebut piyen.

\subsubsection{Nilai Pendidikan Sosial}

Sosial merupakan sesuatu yang berhubungan dengan masyarakat, misalnya hubungan seseorang dengan orang lain, hubungan seseorang dengan kelompok, atau hubungan antarkelompok manusia. Bentuk hubungan tersebut dapat berupa kegiatan kebersamaan ataupun saling bertentangan (Kosasih, 2012: 116). Adapun lawas yang berkaitan dengan nilai sosial sebagai berikut.

\section{Jaga boa bakarante}

na mu pina tu sak ate

bau belo saling beme

(Jaga perkataan saat berbicara

Jangan buat orang sakit hati Agar selalu saling berbagi)

Lawas tersebut mengandung nilai pendidikan sosial khususnya baris ketiga yaitu "Jangan buat orang sakit hati" serta baris keempat yaitu "Agar selalu saling berbagi”. Bait tersebut memberikan makna bahwa masyarakat Sumbawa selalu menjaga perkataan dalam berinteraksi dan berbicara dengan lingkungan sosialnya seperti terlihat pada baris pertama "Jaga perkataan saat berbicara“. Hal tersebut juga mengajarkan kepada anak muda khususnya masyarakat Sumbawa untuk selalu menjaga sopan santun dan perkataan saat berbicara dalam kehidupan sehari-hari. Dengan begitu 
akan tertanam rasa selalu ingin tolongmenolong satu sama lainnya sesuai dengan lawas pada baris keempat, yaitu "Agar selalu saling berbagi".

\section{Nan mu lalo bilen desa}

Pariri mata mu nulang

Peno' turusak kacapa

(Kepergianmu meninggalkan desa

Waspadalah dalam pandangan

Banyak orang rusak karena meremehkan)

Dalam setiap lawas hampir tidak terlepas dalam setiap nasihat, percintaan, dan dunia anak-anak. Jika dicermati secara teliti, setiap jenis lawas tetap mengandung nilai pendidikan. Nilai-nilai tersebut dipoles dengan gaya bahasa yang indah walaupun isinya berupa kritikan tajam ataupun motivasi. Tata cara dalam bahasa itulah yang mengedukasi kita tentang tata cara atau etika komunikasi kepada sesama.

Ajan aku dadi renget Ku nyampe leng papar buret Mana tampo leng mamung entet Areng ka ku bau ngeset

(Andaikan aku jadi nyamuk

Kuhinggap di bokong

Walaupun dihalau baunya kentut

Asalkan bisa kumenggigit)

Nilai pendidikan (edukasi) dari lawas di atas menggambarkan seekor nyamuk yang sedang mencari makan yang sangat susah, tetapi selalu berusaha tanpa putus asa. Lawas itu bisa dijadikan pelajaran bagi manusia untuk tidak putus asa, termasuk dalam mencari nafkah untuk memenuhi kehidupan sehari-hari.

\subsubsection{Nilai Pendidikan Moral}

Nilai moral dalam arti yang luas berkaitan dengan hubungan manusia dengan Tuhan, manusia dengan sesama manusia, dan hubungan manusia dengan alam semesta. Orang yang memiliki moral yang baik adalah orang yang mampu menyeimbangkan ketiga hubungan di atas pada setiap tempat dan waktu (Harahap, 2005:41). Moral menjadi hal mutlak yang harus dimiliki oleh manusia. Moral merupakan istilah yang mengacu pada langkah-langkah manusia atau lainnya yang memiliki nilai positif. Dengan nilai moral diharapakan manusia dapat bersikap baik di masyarakat. Adapun kutipan lawas yang menggambarkan nilai moral sebagai berikut.

lamen balong bakarante tu ramenong bakamore belo notang jangka mate

(Jika tutur kata sopan Orang yang mendengar akan senang Selalu dikenang walau sudah tiada)

242 | Mabasan, Vol. 13, No. 2, Desember 2019, hlm. 231-246 p-ISSN: 2085-9554, e-ISSN: 2621-2005 
Lawas tersebut mengandung nilai pendidikan moral dari baris pertama hingga baris keempat. Khusus pada baris ketiga dalam lawas tersebut mengajarkan untuk selalu menjaga perkataan saat berbicara dengan orang lain agar tidak ada kebencian maupun dendam. Dengan begitu akan tercipta masyarakat yang aman dan rukun. Sikap saling memaafkan akan menjadikan silaturahmi tetap terjalin.

\subsection{Nilai Pendidikan dalam Lawas}

Berdasarkan pemaparan isi lawas di atas dapat diketahui bahwa nilai pendidikan agama yang terkandung di dalam lawas, yakni selalu bersyukur, mengucapkan bismillah dan menyebutkan nama Allah sebelum melakukan sesuatu, sesibuk apapun jangan lupa untuk belajar mengaji, dan jangan pernah tinggalkan salat. Dengan beribadah manusia dapat berserah diri kepada allah Swt. sehingga dapat menjalani hidup dengan penuh kedamaian

Gambaran keadaan masyarakat Sumbawa dapat dilihat dari sejarahsejarah yang terjadi beberapa tahun yang lalu sehingga sampai saat ini terus berkembang dan dikenal oleh masyarakat. Antara bong dan jong merupakan sesuatu yang tidak lepas dari sejarah dan budaya Cina. Para pedagang Cina sudah pernah melakukan hubungan dagang sejak dulu dengan Sumbawa sehingga orang Sumbawa mengenal Candu (dalam bahasa Sumbawa disebut piyen), bong (alat penghisap candu), keramik, sutera, dan uang kepeng (pipis bongkang).

Nilai pendidikan sosial dalam lawas masyarakat Sumbawa mengajarkan tentang cara bersosialisasi dengan sesama, baik antara individu dengan individu, individu dengan kelompok, dan kelompok dengan kelompok. Lawas tersebut mengajarkan untuk selalu menjaga sopan santun dan perkataan saat berbicara serta saling tolong satu sama lain.

Nilai pendidikan moral yang terdapat lawas mengajarkan masyarakat untuk selalu menjaga perkataan saat berbicara dengan orang lain agar tidak ada kebencian. Dengan begitu akan tercipta masyarakat yang aman dan rukun. Adanya saling memaafkan akan memungkinkan terjaganya silaturahmi antarasesama.

\section{Penutup}

Berdasarkan analisis data di atas dapat disimpulkan bahwa nilai-nilai yang terkandung dalam lawas Kabupaten Sumbawa, Nusa Tenggara Barat, yaitu nilai-nilai budaya yang mengadung nilai adat atau kebiasaan-kebiasaan masyarakat 
Sumbawa. Adapun nilai-nilai pendidikan yang terkandung dalam lawas, yaitu nilai pendidikan agama yang mengandung ajaran tentang bagaimana manusia berperilaku dengan Tuhan. Nilai pendidikan sosial yang terkandung dalam lawas, yakni nilai yang memberikan ajaran mengenai perilaku positif dalam kehidupan sehari-hari untuk selalu saling tolong menolong. Nilai pendidikan moral yang terkandung dalam lawas, yaitu berupa nilai-nilai tentang saling menghargai satu sama lain. Sementara itu, nilai pendidikan budaya dan sejarah dalam lawas berhubungan dengan sejarah-sejarah yang terjadi pada zaman dahulu hingga sekarang.

\section{Daftar Pustaka}

Abernathy, J. 2017. 'Poetry Out Loud' in a School Near You. Retrieved Juni 18, $2018 \quad$ From http://www.thespectrum.com/story/l ife/2017/01/15/poetry-out-loudschoolnearyou/96510170/?hootPost ID $=20629 \mathrm{c} 06 \mathrm{a} 9904 \mathrm{e} 0 \mathrm{~d} 059 \mathrm{c} 9 \mathrm{~b} 7 \mathrm{~b} 8 \mathrm{e}$ e8e4c3)

Cantor, J.S. 2006. Fearless InnovationSongwriting for Our Lives: Inspiring Learners with Arts-Based Practices That Support Creativity. Multicultural Education. 14 (2):57-64.
Darmadi, H. 2010. Pendidikan Pancasila Konsep Dasar dan Implementasi. Bandung

Endaswara, S. 2013. Metode Apresiasi Sastra. Yoyakarta: CV. Radhita Buana.

Fathurrohman, M \& Sulistyorini. 2012. Belajar Dan Pembelajaran Meningkatkan Mutu Pembelajaran Sesuai Standar Nasional. Yogyakarta: Teras.

Faturrahman., Ahmadi, K., Amri, S. \& Setyono, H.A. 2012. Pengantar Pendidikan. Jakarta: Prestasi Pustaka Publisher.

Gani, R. 1998. Guruan Sastra Indonesia dan Analisisi. Jakarta: Depdikbud.

Juanda. 2016. Kesadaran Keberagaman dalam Sastra Samawa. Skripsi. Sumbawa: Fakultas Keguruan dan Ilmu Pendidikan Universitas Samawa.

Kane, S., \& Rule, A. C. 2004. Poetry Connections Can Enhance Content Area Learning. Journal of Adolescent \& AdultLiteracy. 47 (8): 658--669.

Kloser, K. 2013. Positive Youth Development Through the Use of Poetry Therapy: Thecontributing Effects Of Language Arts in Mental Health Counseling with Middle School-Agechildren. Journal of Poetry Therapy. 26 (4): 237--253.

Koentjaraningrat. 1980. Metode-Metode Penelitian Masyarakat. Jakarta: Gramedia. 
Kosasih. 2012. Dasar-dasar Keterampilan Bersastra. Bandung: CV. Yrama Widya.

Lafrenière, D., Cox, S. M., Belliveau, G., \& Lea, G. W. 2013. Performing the Human subject: Arts-based Knowledge Dissemination in Health Research. Journal of Applied Arts \& Health. 3 (3): 243--257.

Lickona, T. 2015. Character Matters; Persoalan Karakter, Bagaimana Membantu Anak Mengembangkan Penilaian yang Baik, Integritas dan Kebajikan Penting Lainnya. Jakarta: PT Bumi Aksara.

Mawarni, H. dkk. 2019. Local Wisdom in Lawas (Poetry) Ponan Party Ceremony Society of sumbawa Nusa Tenggara Barat. International Journal odf English Literature and social Sciences (IJELS). 4 (2): 241-247.

Miharja. R. 2012. Buku Pintar Sastra Indonesia. Jakarta: Laskar Aksara.

Hamilton, A.W. 2004. Malay Pantuns. Syney, N.S.W: Australasian Publishing Co. Pry. Ltd

Macionis, J. J. 1970. Society the Basics. New Jersey: Prentice Hall, Englewood Cliffs.

Moleong, L. J. 2010. Metodologi Penelitian Kualitatif. Bandung: Remaja Rosda Karya.

Nurgiyantoro, B. 2015. Stilistika Kultural. Jurnal Widyaparwa. 43 (1): 1--13.

Pradopo, D. 2012. Pengkajian Puisi. Yogyakarta: Gadjah Mada University Press.
Saroni, M. 2012. Pendidikan untuk Orang Miskin: Membuka Keran Keadilan dalam Kesempatan Berpendidikan. Jogjakarta: Ar-ruzz Media.

Sarumpet.R.K.T. 2002. Sastra Masuk Sekolah. Magelang: Indonesatera.

Simecek, K. 2015. Beyond Narrative: Poetry, Emotion and the Perspectival View. British Journal of Aesthetics. 55 (4): 497--513.

Peserta didikntoro. 2010. Metode Penelitian Sastra Analisis Puisi. Yogyakarta: Pustaka Pelajar.

Solihati, N. 2017. Aspek Pendidikan Karakter dalam Puisi Hamka. dalam Litera Jurnal Penelitian Bahasa, Sastra, dan Guruannya. 16 (1). 51--63.

Stovall, D. 2006. Urban Poetics: Poetry, Social Justice and Critical Pedagogy in Education. Urban Review. 38 (1): 63--80.

Sukiman. P. P., \& Widiati, N. 2017 Pengembangan Modul Puisi Rakyat Sumbawa Sebagai Bahan Pembelajaran Sastra Di SMP. Jurnal Pendidikan. 2 (4): 556--561.

Sunaryadi. 2013. Serat Madu Tata Krami dan Relevansinya dengan Pendidikan Karakter. Dalam Litera Jurnal Penelitian Bahasa, Sastra, dan Guruannya. 12 (1): 119--128.

Suparlan. 2015. Mendidik Hati Membentuk Karakter: Panduan AlQur'an Melejitkan Hati Memperindah Karakter. Yogyakarta: Pustaka Belajar Suseno, Tusiran. 2006. Mari Berpantun. Yayasan Panggung Melayu. Jakarta. 
Suwignyo, H. 2013. Makna Kearifan Budaya Jawa dalam Puisi Pariksit, Telinga, Dongeng Sebelum Tidur, dan Asmaradana. Jurnal Bahasa dan Seni. 41 (2): 181--190.

Suyasa, M. 2009. Lawas Samawa dalam Konfigurasi Budaya Sumbawa. Jurnal Mahasan. 3 (1): 86--106.

Teeuw, 1992. Membaca dan Menilai Sastra. Jakarta: Gramedia.

Tilaar, H. A. R. (2015). Pedagogik Teoritis untuk Indonesia. Jakarta: Buku Kompas.

Vala, aroslav. 2011. Exact Research on The Reception of Poetry. International Conference on Education and Educational Psychology, Procedia - Social and Behavioral Sciences, 29 (11), $520-527$.

Venkatalah.N. 2007. Value Education. New Delhi: SB Nangia.

Wellberry, C. 2006. On the Use of Poetry in Medical Education. Retrieved Juni 18, 2018, from http://files.eric.ed.gov/fulltext/EJ10 94960.pdf.

Whalen, S. 2000. Expressing Attitudes and Emotions Through Poetry. Journal of School Health. 70 (7): 301--302.

Zaidan, A. R., dkk. 2000. Kamus Istilah Sastra. Jakarta: Balai Pustaka.

Zakiyah, Q. Y. \& Rusdiana. (2014). Pendidikan Nilai: Kajian Teori dan Praktik di Sekolah. Bandung: CV Pustaka Setia.
Zuhdi, M.H. dkk. 2017. Peta Dakwah Majelis Ulama Indonesia Nusa Tenggara Barat. Mataram: Majelis Ulama Indonesia (MUI) Provinsi NTB

Zakiyah, Q. Y. \& Rusdiana. 2014. Pendidikan Nilai: Kajian Teori dan Praktik di Sekolah. Bandung: CV Pustaka Setia.. 